\title{
Atypical presentation in patients with $17 \alpha$-hydroxylase deficiency caused by a deletion in the CYP17A1 gene: short stature
}

\author{
Semih Bolu ${ }^{1 \oplus}$, Recep Eröz ${ }^{2 \oplus}$, Mehmet Tekin $^{3 \oplus}$, Mustafa Doğan ${ }^{2 \oplus}$ \\ ${ }^{1}$ Division of Pediatric Endocrinology, ${ }^{3}$ Department of Pediatrics, Adryaman University Faculty of Medicine, Adryaman; ${ }^{2}$ Department of \\ Medical Genetics, Düzce University Faculty of Medicine, Düzce, Turkey.
}

\begin{abstract}
Background. Patients with $17 \alpha$-hydroxylase deficiency (17OHD) usually present with tall stature and eunuchoid features, rather than growth retardation. However, unlike the classic form of the disease, short stature due to a lack of pubertal growth spurt and sex hormone deficiency was present in our four cases. We wanted to emphasize that short stature might be the cause of first presentation in patients with $17 \mathrm{OHD}$.

Cases. We report five patients of Kurdish origin with 17 OHD, four of whom had short stature; two presented because of short stature and two were detected as having short stature. The external genitalia had a female appearance and was prepubertal in all cases. Hypertension was also detected in four of the patients. Serum biochemical and hormonal analyses were performed for each patient. Laboratory data suggesting severe growth hormone $(\mathrm{GH})$ deficiency were obtained from one patient, while the other had a familial history suggesting constitutional delay of growth and puberty (CDGP). Whole exome sequence analysis of the CYP17A1 gene was performed on all patients. STR fragment analysis and multiplex ligation dependent probe amplification (MLPA) analysis was also performed to detect mutations associated with congenital adrenal hyperplasia (CAH) in the CYP17A1 gene. No mutation was detected in the whole exome sequence analysis of the CYP17A1 gene in all five patients, although wide deletions were identified in the 1st-6th exons of this gene at MLPA analysis.

Conclusions. Patients with $17 \alpha$-hydroxylase deficiency can present with short stature because they have no pubertal growth spurt during adolescence. Therefore, $17 \mathrm{OHD}$ should be considered in the differential diagnosis of patients with delayed puberty and short stature.
\end{abstract}

Key words: $17 \alpha$-Hydroxylase deficiency, plasma CYP17A1 gene, MLPA analysis, short stature.

$17 \alpha$-hydroxylase deficiency (17 OHD) is a rare autosomal recessive form of congenital adrenal hyperplasia $(\mathrm{CAH})$ with an estimated incidence of 1:50,000-100,000, accounting for $1 \%$ of all CAH cases. ${ }^{1,2}$ Blockage of the pathway catalyzed by $17 \alpha$-hydroxylase stimulates adrenocorticotropic hormone $(\mathrm{ACTH})$, leading to overproduction of corticosterone and 11-deoxycorticosterone

\footnotetext{
Semih Bolu

drsmhbl@hotmail.com
}

Received 29th January 2019, revised 3rd January 2020, 29th February 2020, accepted 16th April 2020.

The study was presented as a poster at 22nd National Pediatric Endocrinology and Diabetes Congress on 18-22 April 2018, Antalya, Turkey.
(11-DOC). ${ }^{3} \quad$ These steroids, which exhibit mineralocorticoid activity, lead to water and sodium retention, and inhibition of renin and aldosterone production. Levels of $17-\mathrm{OH}-$ pregnenolone,

17-hydroxyprogesterone (17OHP), 11-deoxycortisol, cortisol, dehydroepiandrosterone, androstenedione, and testosterone decrease. ${ }^{4}$ Increased sodium reabsorption and high blood volume suppress the renin angiotensin system. Reduced aldosterone levels are therefore observed in most patients with 17 OHD. ${ }^{5}$

17 OHD is characterized by sexual infantilism due to an inability to produce gonadal steroids, primary amenorrhea in women $(46 \mathrm{XX})$, and 
disorders of sex development (DSD) in men (46XY). Decreased production of glucocorticoids also increases ACTH secretion, leading to overproduction of mineralocorticoids, and resulting in hypertension and hypokalemia. ${ }^{6}$ Gonadotropin levels are high during the pubertal period, and androgen and estrogen levels are low. The growth rate in affected patients is slow, but due to delayed epiphyseal plate fusion, these patients keep growing into adulthood and subsequently exhibit tall stature.

In this study, we describe five patients of Kurdish origin with 17 OHD. Short stature was present in four of these patients with 17 OHD. Delayed puberty was also present in all patients and hypertension in four. MPLA analysis revealed wide deletions in the 1st-6th exons of the CYP17A1 gene.

\section{Case Reports}

Five patients who were diagnosed as having 17 OHD were included in this case series. These patients were followed from 2016 to 2019 in the Pediatric Endocrinology Unit of Adiyaman Training and Research Hospital. 17-OHD was suspected in the presence of delayed puberty, hypertension and/or hypokalemia. Diagnosis of the disease was established based on clinical observations, typical laboratory findings, and molecular features. Routine serum and urine biochemical analyses and hormonal evaluations including cortisol, ACTH, progesterone, $17 \mathrm{OHP}$, androstenedione, DHEA-S, luteinizing hormone (LH), follicle-stimulating hormone (FSH), estradiol (E2), testosterone, aldosterone, and plasma renin activity (PRA) levels were conducted for each patient. All patients underwent karyotype analyses and mutational analysis of the CYP17A1 gene. The study protocol was approved by the Institutional Ethics Committee of Adryaman University Faculty of Medicine (Decision number 2-3/20.03.2018). Written informed consent was obtained from all participants.

\section{Genomic DNA Preparation and PCR Amplification of the CYP17A1 Gene}

Genomic DNA was isolated, and whole exome sequence analysis of the CYP17A1 gene was performed. Additionally, STR fragment and MLPA analysis were performed for the detection of mutations (large deletions/duplications) associated with $\mathrm{CAH}$ in the CYP17A1 gene. A SALSA MLPA P0334 Gonadal kit (MRC, Holland) was used for the MLPA test.

\section{Case 1 (Index patient)}

A 12-year-old girl presented with hypopotassemia. The parents were first-degree cousins, but the family history was otherwise unremarkable. The family pedigree is shown in Figure 1. In a physical examination, her external genitalia was female appearance and prepubertal. Her blood pressure was high $(148 / 96 \mathrm{~mm} \mathrm{Hg})$. The patient's weight was $34.2 \mathrm{~kg}(-2.46 \mathrm{SDS})$, height was $144.4 \mathrm{~cm}(-2.23$ SDS), with a target height of $165 \mathrm{~cm}$ (0.32 SDS), and the bone age was delayed. Laboratory investigations revealed a low serum potassium concentration and renin level, and a high progesterone level (17.22; normal range: 0.1-1.3 $\mathrm{ng} / \mathrm{mL}$ ). Androgen levels are shown in Table I. The maximum cortisol response to the standarddose ACTH stimulation test was insufficient (Table II). The patient's karyotype was $46 \mathrm{XY}$ and SRY (+). A deletion in the 1st -6 th exons of the CYP17A1 was detected following STR fragment and multiplex ligation dependent probe amplification (MLPA) analysis (Fig. 2).

\section{Case 2}

A 13-year-old girl presented to the pediatric endocrinology outpatient clinic with short stature. The parents were second-degree cousins. The family pedigree is given in Figure 1. In a physical examination, her external genitalia was female appearance and prepubertal. Her blood pressure was high (130/76 mm Hg). The patient's weight was $39.4 \mathrm{~kg}$ (-1.92 SDS), height was $143.4 \mathrm{~cm}(-2.70$ SDS), with a target height

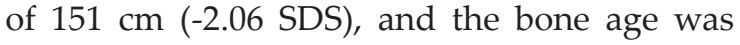


Table I. Clinical, biochemical and genetical features of the cases.

\begin{tabular}{|c|c|c|c|c|c|}
\hline Case & Case 1 & Case 2 & Case 3 & Case 4 & Case 5 \\
\hline Cause of admission & Hypopotassemia & Short Stature & Amenorrhea & Short Stature & Hypertensiyon \\
\hline Age & 12.9 & 13.6 & 15.5 & 12.9 & 14.9 \\
\hline Bone age & 9 & 10.5 & 10.5 & 10.5 & 9.5 \\
\hline Hypertension & + & + & + & - & + \\
\hline $\begin{array}{l}\text { Breast development } \\
\text { (Tanner stage) }\end{array}$ & 1 & 1 & 1 & 1 & 1 \\
\hline Pubic hair (Tanner stage) & 1 & 1 & 1 & 1 & 1 \\
\hline Karyotype & $46, \mathrm{XY}(\mathrm{SRY}+)$ & $46, X X$ & $46, X Y(S R Y+)$ & $46 X X$ & $46 \mathrm{XY}(\mathrm{SRY}+)$ \\
\hline $\mathrm{Na}, \mathrm{mmol} / \mathrm{l}(135-145)$ & 133 & 143 & 143 & 138 & 139 \\
\hline $\mathrm{K}, \mathrm{mmol} / \mathrm{l}(3.5-5.5)$ & 2.4 & 2.9 & 3.3 & 4.3 & 3.8 \\
\hline $\begin{array}{l}\text { Testosterone, } \mathrm{ng} / \mathrm{ml} \\
(0.1-0.75)\end{array}$ & 0.36 & 0.23 & 0.08 & 0.12 & 0.23 \\
\hline LH, IU/1 & 22.16 & 33 & 29.92 & 34.65 & 21.64 \\
\hline FSH, IU/1 & 100.61 & 80.87 & 79.23 & 79.37 & 74.53 \\
\hline Estradiol, pg/ml & 4 & 33 & 12 & 15 & 12 \\
\hline $\begin{array}{l}\text { Aldosterone, } \mathrm{ng} / \mathrm{dl} \\
(3.5-30)\end{array}$ & 10.4 & 55.49 & 30 & 23.2 & 20.48 \\
\hline $\begin{array}{l}\text { Renin, } \mathrm{mcg} / \mathrm{ml} / \mathrm{saat} \\
(0.5-5)\end{array}$ & 0.15 & 0.31 & 0.11 & 0.10 & 0.13 \\
\hline
\end{tabular}

ACTH: adrenocorticotropic hormone, LH: luteinizing hormone, FSH: follicle-stimulating hormone.

Table II. ACTH stimulation test results.

\begin{tabular}{lccccc}
\hline Case & Case 1 & Case 2 & Case 3 & Case 4 & Case 5 \\
\hline ACTH, pg/ml (0-46) & 66.7 & 379 & 1250 & 1000 & 597 \\
Cortisol $(\mu \mathrm{g} / \mathrm{dl})(5-25)$ & & & & & \\
Basaline & 0.44 & 0.75 & 0.26 & 0.23 & 0.22 \\
Peak & 0.74 & 1.01 & 0.31 & 0.26 & 0.25 \\
Progesterone (ng/ml) (0.3-1.5) & & & & & \\
Basaline & 17.22 & 14.89 & 10.99 & 8.51 & 7.81 \\
Peak & 19.32 & 16.46 & 15.12 & 12.89 & 13.16 \\
17-OH progesterone (ng/ml) (0.2-1.3) & & & & & \\
Basaline & 0.88 & 1.18 & 0.61 & 0.88 & 0.76 \\
Peak & 0.94 & 1.23 & 0.76 & 1.09 & 1.01 \\
Androstenedione (ng/ml) (0.75-3.1) & & & & & \\
Basaline & 0.16 & 0.06 & 0.08 & 0.02 & 0.1 \\
Peak & 0.21 & 0.09 & 0.1 & 0.04 & 0.15 \\
DOC (ng/dl) (0.12-0.6) & & & & & \\
Basaline & 1.35 & 3.66 & 2.64 & 1.24 & 1.82 \\
Peak & 1.84 & 3.88 & 2.7 & 1.26 & 2.24 \\
DHEA-S ( $\mu$ gg/dl) (35-430) & & & & & \\
Basaline & 3.1 & 4.7 & 3.4 & 4.8 & 4.4 \\
Peak & 3.4 & 5.2 & 3.8 & 5.4 & 4.9 \\
\hline
\end{tabular}



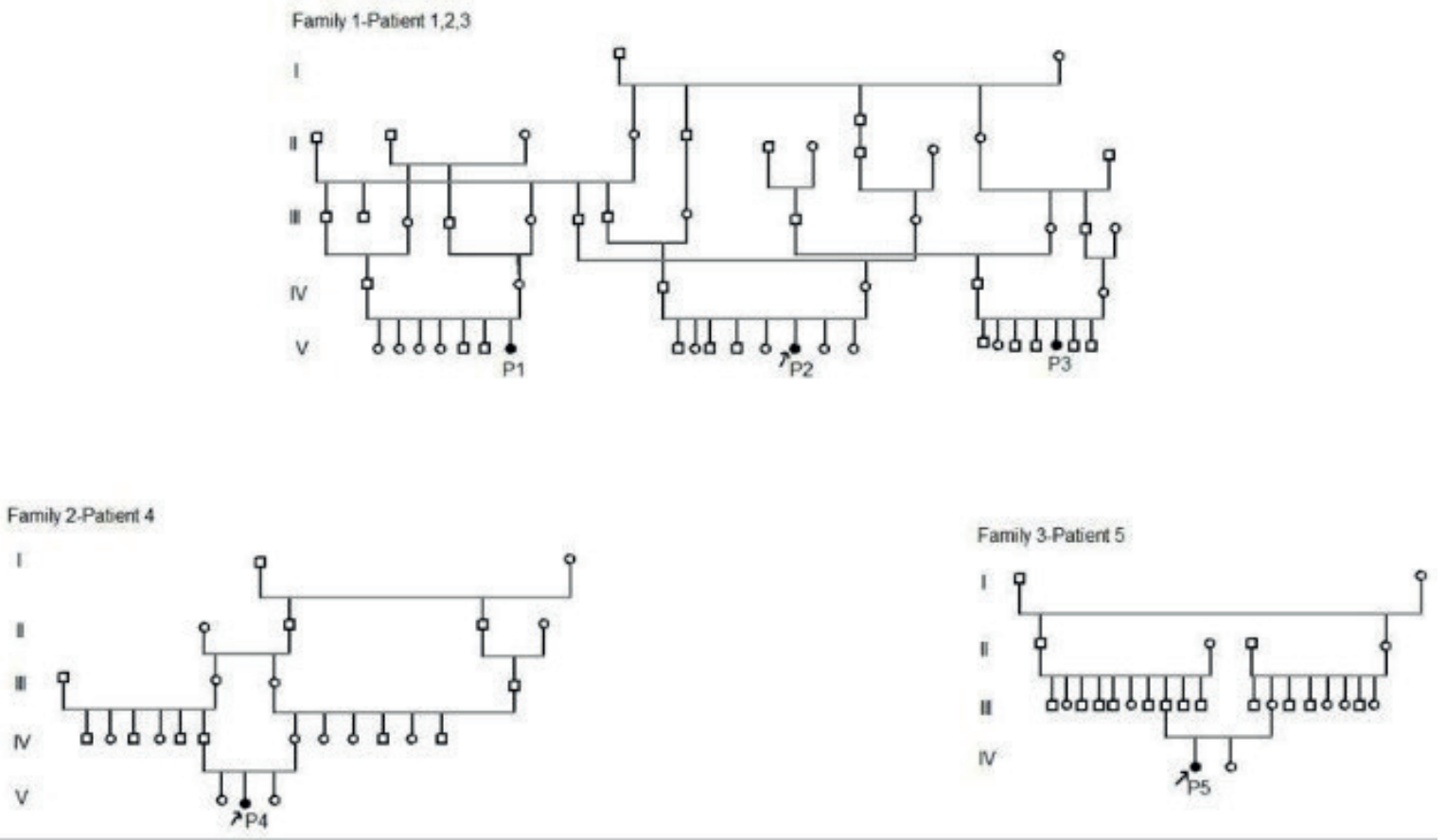

Fig. 1. Family pedigree of the cases.

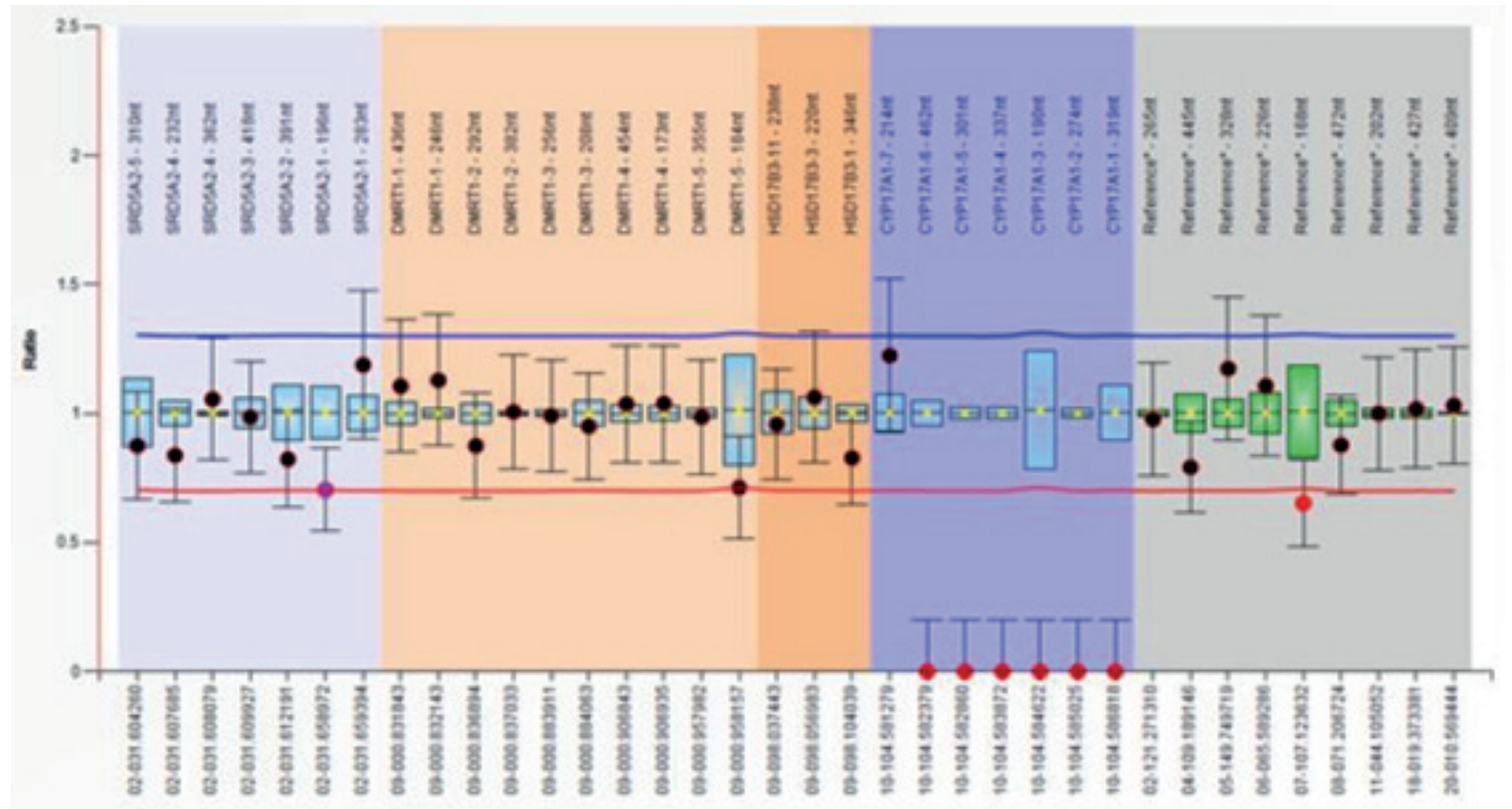

Fig. 2. Detected deletion in 1st - 6th exons of the CYP17A1 gene.

delayed. Laboratory investigations revealed a low serum potassium concentration and suppressed renin level, and a high progesterone concentration (14.89 ng/ml). The maximum cortisol response to the standard-dose ACTH stimulation test was insufficient (Table II). The maximum response to the growth hormone (GH) stimulation test, which was performed in an external center, was insufficient (L-dopa: $0.6 \mathrm{ng} / \mathrm{mL}$, and clonidine: $1.2 \mathrm{ng} / \mathrm{ml}$ ). Priming 
in this patient with delayed puberty was performed with the administration of $40 \mu \mathrm{g} /$ $\mathrm{m}^{2}$ /day ethinyl estradiol for three days, after which a sufficient $\mathrm{GH}$ response was achieved in the GH stimulation test (L-dopa: $11.2 \mathrm{ng} / \mathrm{mL}$ ). The patient's karyotype was 46 XX. A deletion in the 1st - 6th exons of the CYP17A1 gene was detected following STR fragment and MLPA analysis (Fig. 2).

\section{Case 3}

A 15-year-old girl was referred from the gynecology outpatient clinic due to hypergonadotropic hypogonadism and $46 \mathrm{XY}$ sexual development disorder. The parents were first-degree cousins. The family pedigree is shown in Figure 1. In a physical examination, her external genitalia was female appearance and prepubertal. Her blood pressure was high (148/96 mm Hg). The patient's weight was 42.3 $\mathrm{kg}$ (-2.35 SDS), height was $158.5 \mathrm{~cm}(-0.61$ SDS), with a target height was $166 \mathrm{~cm}$ (0.49 SDS), and the bone age was delayed. Laboratory investigations showed a low serum potassium concentration and suppressed renin level, whereas the progesterone was high (15.12 ng/ $\mathrm{mL}$ ). The maximum cortisol response to the standard-dose ACTH stimulation test was insufficient (Table II). The patient's karyotype was $46 \mathrm{XY}$ and SRY (+). A deletion was detected in the 1st - 6th exons of the CYP17A1 gene following STR fragment and MLPA analysis (Fig. 2).

Case 1 (index patient), case 2, and case 3 presented to the pediatric endocrinology outpatient clinic independently of each other and at different times. As a result of clinical and laboratory evaluations, it was noticed that these patients, who were diagnosed as having 17OHD, had the same surname, and in detailed questioning, these three patients were found to be distant relatives.

\section{Case 4}

A 12-year-old girl presented because of short stature. The parents were first-degree cousins, but the family history was unremarkable. The family pedigree is shown in Figure 1. In a physical examination, her external genitalia was female appearance and prepubertal. Her blood pressure was normal (110/70 mm Hg). The patient's weight was $37.9 \mathrm{~kg}$ (-1.26 SDS), height was $143.5 \mathrm{~cm}$ (-1.83 SDS), with a target height was $162 \mathrm{~cm}$ (-0.19 SDS), and the bone age was delayed. Laboratory investigations showed normal serum sodium and potassium concentrations, but high progesterone levels (8.51 ng/mL). The maximum cortisol response to the standard-dose ACTH stimulation test was insufficient (Table II). The patient's karyotype was 46 XX. A deletion in the 1st - 6th exons of the CYP17A1 gene was detected following STRE fragment and MLPA analysis (Fig. 2).

\section{Case 5}

During hospitalization for the correction of prominent ears, a 14-year-old girl was detected as having hypertension. We learned that the parents were first-degree cousins, and that the patient had undergone surgery at the age of 3 years for bilateral inguinal hernia. The family pedigree is shown in Figure 1. The mother reported that her first child, a girl, reached puberty late, had late growth, and that this child who had no chronic disease had regular menstruation and had similar height as her peers. At physical examination, her external genitalia was female appearance and prepubertal. Her blood pressure was high (135/100 mm Hg). The patient's weight was $38.6 \mathrm{~kg}$ (-2.65 SDS), height was $149.5 \mathrm{~cm}$ (-1.94 SDS), with a target height was $164 \mathrm{~cm}$ (0.15 SDS), and the bone age was delayed. Laboratory investigations showed normal serum sodium and potassium concentrations, but her progesterone level was high $(7.81 \mathrm{ng} / \mathrm{mL})$. The patient's karyotype was $46 \mathrm{XY}$ and SRY (+). A deletion in the 1st 6th exons of the CYP17A1 gene was detected following STR fragment and MLPA analysis (Fig. 2).

The clinical and laboratory features of all patients at presentation are shown in Table I. The ACTH stimulation test was started at 08:00 
A.M. Initial blood samples were collected, and 30 and 60 minutes after intravenous $250 \mu \mathrm{g}$ synthetic ACTH 1-24 administration.

\section{Discussion}

CYP17A1 gene mutations occur in different patterns including point mutations, small deletions and insertions, splice site alterations, and rarely, large deletions. ${ }^{7}$ These mutations may exhibit ethnic variations.

Most patients with 17 OHD typically present with hypertension and primary gonadal insufficiency during adolescence and adulthood. Hypertension may be detected at the time of diagnosis, from infancy to the fifth decade of life, and usually in patients presenting due to delayed puberty. ${ }^{8,9}$ When diagnosis is established in these patients, adequate treatment should be initiated in order to prevent complications such as hypertension and hypokalemia, and in order to ensure the appearance of secondary sexual characteristics in an appropriate time..$^{10}$

The defect in sex steroid production causes ambiguous genitalia or female external genitalia (46 XY sexual development disorder) in affected males and delayed puberty and primary amenorrhea in affected females. ${ }^{11}$

Tall stature may be seen at initial presentation in patients with $17 \mathrm{OHD} .{ }^{12}$ The apparently tall stature in individuals with $17 \mathrm{OHD}$ and $\mathrm{XY}$ karyotype can be due to using growth charts developed for females. Height is dependent upon linear bone growth. ${ }^{13}$ Regulation of linear bone growth in children and adolescents involves a complex interaction of hormones and growth factors. GH is considered as the key hormone regulator of linear growth in childhood. ${ }^{14}$ Sex steroids play a crucial role in pubertal growth, both at the systemic level via the GH/insulin-like growth factor-1 (GH/IGF1) axis, and at the local level of the epiphyseal growth plate. Estrogen is a critical hormone for controlling growth plate acceleration and fusion in both sexes. ${ }^{15}$ Epiphyseal closure is delayed in patients with 17 OHD because of the lack of estrogen in the growth plate, and the final height is therefore above average in late adolescent or adult patients. In contrast, Ma et al. ${ }^{13}$ reported a patient with $17 \mathrm{OHD}$ and short stature at the time of admission, whose height reached $152 \mathrm{~cm}$ following glucocorticoid and sex steroid replacement. In addition, Kardelen et al. ${ }^{16}$ determined short stature at presentation in three out of six patients (50\%) with $17 \mathrm{OHD}$. One common feature of these patients is that growth can occur without the need for GH. Similarly, in the present study, four of our patients had short stature at presentation. Sex steroids could not be started in case 1 because the family could not be convinced of the benefits of drug therapy. The growth rate in case 1 was therefore lower compared with the other patients who did receive sex steroids. A number of variables can directly or indirectly affect the pubertal growth spurt, including sex, genetics, nutrition, endocrine regulation, physical activity, and ethnicity. ${ }^{17}$ The absence of a pubertal growth spurt caused by an absence of sex steroids in patients with 17 OHD may explain the short stature in these cases.

Sex steroids regulate GH release either directly, or else indirectly through IGF-1, and GH secretion increases with pubertal development. Some studies have reported rare transient partial growth hormone deficiency as a result of GH stimulation testing in patients with delayed puberty. ${ }^{18,19} \mathrm{GH}$ test outcomes may be low such as to occasionally suggest growth hormone deficiency in patients with 17 OHD presenting with prepubertal short stature. This may derive from sex steroid deficiency. Priming with sex steroids should therefore be performed in these patients before GH stimulation tests. Diagnostic confusion may be experienced at first presentation in patients with 17 OHD with short stature, as in our case 2, in which the GH stimulation test suggested severe GH deficiency, and case 5, with a history of constitutional delay of growth and puberty (CDGP), and with delayed puberty and delayed bone age. 
This study reports five cases from three different Kurdish families with partial deletions between exons 1 and 6 in the CYP17A1 gene in order to add their clinical and molecular characteristics to the existing literature. All our patients were living in the Adryaman province of Southeastern Turkey, and this identical gene deletion seen in different families may be explained by the founder effect.

In conclusion, wide deletions in exons 1-6 of the CYP17A1 gene disrupt 17 alpha / 17,20 lyase enzyme activity, leading to severe phenotypic alterations. Causes of presentation in patients with same genotypic changes may range from delayed puberty and hypertension to hypopotassemia and short stature. 17 OHD should be ruled out with clinical and laboratory investigations including blood pressure measurement in patients presenting with delayed puberty and short stature before diagnosing CDPG or GH deficiency. Further multicenter studies are now warranted in order to better evaluate the relationship between CYP17A1 gene mutations and short stature.

\section{REFERENCES}

1. Krone N,Arlt W. Genetics of congenital adrenal hyperplasia. Best Pract Res Clin Endocrinol Metab 2009; 23: 181-192.

2. Oh YK, Ryoo U, Kim D, et al. 17alpha-hydroxlyase/17, 20-lyase deficiency in three siblings with primary amenorrhea and absence of secondary sexual development. J Pediatr Adolesc Gynecol 2012; 25: e103-e105.

3. Costa-Santos M, Kater CE, Dias EP, Auchus RJ. Two intronic mutations cause 17-hydroxylase deficiency by disrupting splice acceptor sites: direct demonstration of aberrant splicing and absent enzyme activity by expression of the entire CYP17 gene in HEK-293 cells. J Clin Endocrinol Metab 2004; 89: $43-48$

4. Biason-Lauber A, Boscaro M, Mantero F, Balercia G. Defects of steroidogenesis. J Endocrinol Invest 2010; 33: 756-766.

5. Biglieri EG. Mechanisms establishing the mineralocorticoid hormone pattern in the 17-hydroxylase deficiency syndrome. J Steroid Biochem 1979; 11(1B): 653-657.
6. Auchus RJ. The genetics, pathophysiology, and management of human deficiencies of P450c17. Endocrinol Metab Clin North Am 2001; 30: 101-119.

7. Auchus RJ. Steroid 17-hydroxylase and 17,20-lyase deficiencies, genetic and pharmacologic. J Steroid Biochem Mol Biol 2017; 165(Pt A): 71-78.

8. Kota SK, Modi K, Jha R, Mandal SN. 17- $\alpha$-hydroxylase deficiency: an unusual case with primary amenorrhea and hypertension. Indian J Endocrinol Metab 2011; 15: 127-129.

9. Britten FL, Ulett KB, Duncan EL, Perry-Keene DA. Primary amenorrhoea with hypertension: undiagnosed 17- $\alpha$-hydroxylase deficiency. Med J Aust 2013; 199: 556-558.

10. Kim SM, Rhee JH. A case of 17 alpha-hydroxylase deficiency. Clin Exp Reprod Med 2015; 42: 72-76.

11. Biason-Lauber A, Boscaro M, Mantero F, Balercia G. Defects of steroidogenesis. J Endocrinol Invest 2010; 33: 756-766.

12. Dhir V, Reisch N, Bleicken CM, et al. Steroid 17alphahydroxylase deficiency: functional characterization of four mutations (A174E, V178D, R440C, L465P) in the CYP17A1 gene. J Clin Endocrinol Metab 2009; 94 : 3058-3064.

13. Ma L, Peng F, Yu L, et al. Combined $17 \alpha$-hydroxylase/17,20-lyase deficiency with short stature: case study. Gynecol Endocrinol 2016; 32: 264-266.

14. Juul A. The effects of oestrogens on linear bone growth. Hum Reprod Update 2001; 7: 303-313.

15. Kerrigan JR, Rogol AD. The impact of gonadal steroid hormone action on growth hormone secretion during childhood and adolescence. Endocr Rev 1992; 13: 281-298.

16. Kardelen AD, Toksoy G, Baş F, et al. A rare cause of congenital adrenal hyperplasia: clinical and genetic findings and follow-up characteristics of six patients with 17-hydroxylase deficiency including two novel mutations. J Clin Res Pediatr Endocrinol 2018; 10: 206-215.

17. Soliman A, De Sanctis V, Elalaily R, Bedair S. Advances in pubertal growth and factors influencing it: can we increase pubertal growth? Indian J Endocrinol Metab 2014; 18(Suppl 1): S53-S62.

18. Gourmelen M, Pham-Huu-Trung MT, Girard F. Transient partial hGH deficiency in prepubertal children with delay of growth. Pediatr Res 1979; 13: 221-224.

19. Longobardi S, Merola B, Pivonello R, et al. Reevaluation of growth hormone $(\mathrm{GH})$ secretion in 69 adults diagnosed as $\mathrm{GH}$-deficient patients during childhood. J Clin Endocrinol Metab 1996; 81: 12441247. 